\title{
Who Supported the Strong Preventive Measures During the Covid-19 Pandemic?
}

\author{
Jinghui Wang ${ }^{1, a}$ \\ ${ }^{1}$ Greenwood laboratory school, Springfield, Mo 65806, USA \\ aEmail:wjhsqux@163.com
}

\begin{abstract}
The current Coronavirus pandemic has caused large-scale negative consequences to the economic developments as well as the society on a global scale. To prevent the further spreading of the virus, most governments have put forward a set of very strong measures that restrict citizen's freedom to some extent (the most striking examples are the series of measurements taken during the lockdown phase). However, it is yet well established who might follow these measurements and who might not. The current study offers an innovative look at the personal characteristics that may link to one's support for these strong preventive measures. The survey study found no supportive evidence for the positive relationships between disgust sensitivity as well as of patriotism to one's support to strong preventive measures. The interviews conducted further suggest that people's support for the policies might decrease over time and that one might only support the policies when it's absolutely necessary. The paper also discusses implications, limitations, and future directions of the current study.
\end{abstract}

Keywords: Disgust sensitivity, Covid-19, Patriotism

\section{INTRODUCTION}

The COVID-19 virus outbreak originated from Wuhan City, Hubei Province, the People's Republic of China in December 2019, and quickly spread to the world in 2020, which subsequently caused a pandemic on a global scale. The pandemic has been described by many international organizations and the media as the most severe crisis - especially in the public health domain - the world faces ever since the Second World War. As of October 25, 2020, there have been 42.554 million confirmed cases worldwide, of which 1.14 million have caused mortality. In China alone, the current COVID-19 pandemic has caused 4,739 deaths until October 28, 2020, which is about $5.2 \%$ of the total number of infections.

Such a pandemic at the global scale not only caused great loss of lives and economic developments but also brought about a huge negative impact on people's psychological state. To mitigate the profound negative consequence, the central government of each country serves as the organizer and the central commander of emergency management forces and put forward various forceful measures to prevent the further spread of the disease. However, as these measures largely restricted people's freedom at an unprecedented scale - a most striking example is the set of policies proposed during the "lockdown" period, which enforced all of the restaurants, gyms, bars, and theatres to be entirely closed down numerous violations were reported all over the world. Many people - especially the younger ones who might only showcase mild symptoms - consistently broke the restrictive measures and enjoyed their parties and gatherings freely. These disruptive behaviors expectedly led to very serious consequences: starting from midSeptember, a second wave hit the States as well as the European countries at an exaggerating rate. Therefore, it is pertinent and timely to identify the group of people who might violate the strong policy imposed by the government during the pandemic. As such, the preventive strategy could target this deviant group and thereby even more effectively protect the vulnerable elderly as well as the society at large.

To respond to the open call of social and behavioral research on COVID-19 (Gruber, 2020) [1], one of the major contributions of the current research was to identify the personal-level predictors of the level of support to government's preventive policies by investigating the role of disgust sensitivity and (blind) patriotism. The concept of disgust sensitivity refers to the individual differences in originating the emotion of disgust. It has been first proposed in Haidt et al., (1994) [2] and has been viewed as a self-protect mechanism 
resulted from the evolutionary process to prevent human beings from large-scale pathogens (Inbar et al., 2012) [3]. In previous research, it has been found to be one of the main predictors of anxiety during the H1N1 (swine flu) pandemic (Wheaton et al., 2012) [4] and the Ebola pandemic (Beall et al., 2016) [5]. In some pioneering research conducted in the context of the current COVID19 pandemic, similarly, the extent of disgust sensitivity has been found to be closely related to coronavirus anxiety and safety behaviors (Cox et al., 2020) [6]. Diaz \& Cova (2020) [7] has offered direct evidence for the connection between trait disgust sensitivity and support for preventive policies - with a US sample, they found the trait pathogen disgust was positively related to compliance with official recommendations. A part of the current research replicates and extends this finding in a Chinese sample. I, therefore, propose Hypothesis 1:

Hypothesis 1: Trait disgust sensitivity is positively linked to support to preventive policies

Furthermore, we investigated the role of blind patriotism in determining one's support for preventive policies. According to the previous research, blind patriotism, a form of patriotism that is characterized as irrational, was closely related to one's support to fight against the outgroups (Sahar, 2008) [8] as well as defensive responses to national threats (Barne et al., 2014) [9]. As the coronavirus as its disruptive form could be viewed as a form of national threats (this was also widely used in media coverage), we could therefore propose Hypothesis 2.

Hypothesis 2: Blind Patriotism is positively linked to support to preventive policies

Last, as trait disgust sensitivity and blind patriotism refer to two distinctive components of individual differences, we also expect an interaction effect of the two variables, as formulated in Hypothesis 3.

Hypothesis 3: Blind Patriotism facilitates the positive effect of disgust sensitivity on support to preventive policies

The three hypotheses will be explicitly tested in a survey that consists of more than 200 respondents. To offer a comprehensive view of the driving factors of support to preventive measures, in addition to quantitative analysis, we have also conducted a qualitative study in which we have asked the participants to reveal the fundamental reasons to support the preventive policies.

The remaining part will be organized as follows. In the second and third sections, the method and results of the survey study are presented, respectively. The fourth section is dedicated to brief reports of the interviews conducted as a supplement to the quantitative analysis. Last, we discuss the implication, limitation, and future directions of the current line of research.

\section{METHOD}

\subsection{Sample}

The respondents of the current survey were residents from three provinces: Jiangsu, Zhejiang, and Shanghai. I collected all of the responses through social media Wechat with a snow-ball sampling method while the respondents took part in the survey on a voluntary basis. The sample consisted of a total of 227 people, of which 66 were male and 161 were female. The average age of the respondents was. For the XX incomplete cases, the multiple imputations (MI; Buuren \& GroothuisOudshoorn, 2010) [10] procedure was applied to impute the missing values.

\subsection{Measures}

\subsubsection{Disgust sensitivity}

Haidt et al. (1994) [2] developed a popular scale consists of seven sub-scale - to measure disgust sensitivity that adapted their own framework. In the current context of the pandemic, I considered the most relevant subscale of the original disgust sensitivity scale to be the subscale Death and Hygiene, as both were heatedly discussed issues in media coverage of the pandemic, and both were directly linked with the pathogen. The subscale consists of eight items, and the respondents were asked to report their agreements with each of the items on a 7-point Likert scale. The reliability of the current scale was ....

\subsubsection{Patriotism}

The level of blind and constructive patriotism was measured by a 7 -item scale that was adapted from Schatz et al., (1999) [11]. Again, the respondents were asked to report their agreements with each of the items on a 7point Likert scale. The reliability of the current scale was ....

\subsubsection{Satisfaction on the preventive policies}

Participants were required to self-report their satisfaction with the five listed policies. The five policies were selected from a pool of over twenty Covid - related policies by two independent judges for their perceptiveness and importance. The participants rated on a 7-point Likert scale, ranging from "totally not support" (1) to "totally support" (7). As the five policies covered different perspectives of Covid - related social issues, there is no reason to expect high internal reliability of the five ratings. Instead, I directly used the mean score of the five ratings as the indicator of the overall satisfaction with the preventive policies. 


\subsubsection{Control variables}

To partial out potential confounders, I have included the following variables as control variables in the current analysis: age, gender, and subjective rating of the income level.

\subsection{Analysis of Strategy}

The step-wise regression procedure was applied in the current analysis. Especially, I have constructed three regression models with increased complexities. The first model only included all control variables as predictors. In the second model, the main effects of both disgust sensitivity and blind patriotism were entered into the model. Finally, the interaction of the two factors was further added to the third model.

\subsection{Results}

To inspect the variables as well as the relationships between them preliminarily, the means, standardizations, and the correlations of the variables are presented in Table 1, together with the confidence intervals of correlations. Interestingly, the participant's self-reported subjective level of income was positively related to patriotism and support for strong protective measures. It should be noted that a consistent finding in political psychology is that the income level is positively related to conservative political ideology. This is in line with the current finding as both patriotism and the support for protective measures are important indicators of conservative ideologies.

Table 1. Means, standard deviations, and correlations between variables

\begin{tabular}{|c|c|c|c|c|c|c|c|}
\hline Variable & $M$ & $S D$ & 1 & 2 & 3 & 4 & 5 \\
\hline 1. Sex & 0.29 & 0.46 & & & & & \\
\hline 2. Age & 42.53 & 11.28 & $\begin{array}{c}-.10 \\
{[-.23, .03]}\end{array}$ & & & & \\
\hline 3. Income & 4.26 & 1.67 & $\begin{array}{c}.08 \\
{[-.05, .21]}\end{array}$ & $\begin{array}{c}.14^{*} \\
{[.01, .27]}\end{array}$ & & & \\
\hline $\begin{array}{l}\text { 4. Disgust } \\
\text { sensitivity }\end{array}$ & 5.42 & 1.36 & $\begin{array}{c}-.25^{\star *} \\
{[-.37,-.12]}\end{array}$ & $\begin{array}{c}.07 \\
{[-.06, .20]}\end{array}$ & $\begin{array}{c}.11 \\
{[-.02, .23]}\end{array}$ & & \\
\hline 5. Blind patriotism & 4.91 & 1.20 & $\begin{array}{c}-.04 \\
{[-.17, .09]}\end{array}$ & {$\left[\begin{array}{c}.38^{\star *} \\
{[.26, .49]}\end{array}\right.$} & {$\left[\begin{array}{c}.20^{\star *} \\
{[.08, .33]}\end{array}\right.$} & {$[.31, .52]$} & \\
\hline $\begin{array}{l}\text { 6. Support the } \\
\text { protective } \\
\text { measures }\end{array}$ & 5.26 & 1.41 & $\begin{array}{c}.06 \\
{[-.07, .18]} \\
\end{array}$ & $\begin{array}{c}-.00 \\
{[-.13, .13]}\end{array}$ & $\begin{array}{c}.15^{\star} \\
{[.03, .28]}\end{array}$ & $\begin{array}{c}.06 \\
{[-.07, .19]} \\
\end{array}$ & $\begin{array}{r}.05 \\
{[-.08, .18]}\end{array}$ \\
\hline
\end{tabular}

We then proceed to conduct a series of step-wise regression analysis to test our hypothesis. The results of these analyses are reported in Table 2 . Inspecting the results of the three models, it can be concluded that the only variable that was related to the level of support to strong protective measures was the self-reported income level. However, as evident in the models of steps 2 and 3, disgust sensitivity, blind patriotism, and the interaction between the two were not significantly correlated with the level of support to strong protective measures. Therefore, the results did not support any of our three hypotheses.

Table 2. The results of step-wise regression analysis

\begin{tabular}{cccccc}
\hline Step & Predictor & $b$ & $b$ & \multicolumn{2}{c}{ Fit } \\
& (Intercept) & $4.77^{* *}$ & {$[3.95,5.59]$} & & \\
Step 1 & sex & 0.13 & {$[-0.28,0.53]$} & & \\
& age & -0.00 & {$[-0.02,0.01]$} & & \\
& income & $0.13^{*}$ & {$[0.02,0.24]$} & & \\
& & & & $R^{2}=.026$ \\
Step 2 & (Intercept) & $4.45^{* *}$ & {$[3.34,5.55]$} & & \\
& sex & 0.17 & {$[-0.25,0.60]$} & &
\end{tabular}




$\begin{array}{ccc}\text { age } & -0.00 \\ \text { income } & 0.12^{*} \\ \text { Disgust } & 0.06 \\ \text { sensitivity } & 0.01 \\ \text { Patriotism } & \\ & \text { (Intercept) } & 4.44^{* *} \\ & \text { sex } & 0.17 \\ & \text { age } & -0.00 \\ & \text { income } & 0.12^{*} \\ & \text { Disgust } & 0.06 \\ & \text { sensitivity } & 0.01 \\ \text { Patriotism } & -0.00 \\ & \text { Disgust }{ }^{*} & \\ & \text { Patriotism } & \end{array}$

[-0.02, 0.01]

$[-0.10,0.22]$

$[-0.18,0.19]$

$R^{2}=.030$

$[1.57,7.32]$

$[-0.25,0.60]$

$[-0.02,0.01]$

[0.01, 0.24]

$[-0.46,0.58]$

$[-0.61,0.63]$

$[-0.11,0.11]$

Note. $b$ are regression coefficients, and the confidence interval of these coefficients are reported in the section '95\%CI'. * indicates $p<.05$. ** indicates $p<.01$.

\section{INTERVIEW}

The interviewees were two males and two females, with an average age of 22 . All of them were students from either senior high school or undergraduate studies. The interviews were conducted with a semi-structured format and each lasted for 30-60 minutes.

All of the four interviewees heartfully supported the preventive policies listed in our survey study, even though two of the interviewees admitted that the measures have actually caused serious inconvenience and disruptions to their normal life and personal schedules (they were scheduled to fly back home during the summer vacation; however, because of the very strong policy imposed by the Chinese government, a large number of flights were canceled and they could only stay in the States). All of the interviewees thought the very strong measures enforced by the Chinese government were necessary and timely to prevent the further spread of the coronavirus and the much more loose measures taken by European countries and the States were way too weak to be effective. The fundamental drivers of their strong support appeared to be the fear of infection. One of the interviewees said, "Maybe such a policy brings a lot of inconveniences; but having viewed so many examples of people suffering the consequence of infection, I am really worried about being infected and I thus support strong measures to be taken". Interestingly, all of the interviewees also revealed that their support for strong measures might diminish for the time being, "I feel that this state should not last too long; if such a policy is permanent, I may feel dissatisfied."

\section{CONCLUSION}

As the pandemic caused by the novel coronavirus is still hitting hard at a global scale at the moment and did not seem to be well-controlled, it becomes increasingly pertinent to understand the antecedents of following the strong protective measures proposed by each government. While these measures might restrict people's freedom to some extent, they are proved to be the most effective way to control the spread of the disease. The current research contributes to the literature and the practice by investigating the relationships between two important individual differences - namely disgust sensitivity and blind patriotism - and one's support to these strong protective measurements. Through a survey study, I did not find support to all of our hypotheses such that neither disgust sensitivity nor blind patriotism was found to be correlated to one's support to strong protective measurements. However, surprisingly, the self-reported income level was found to be positively related to one's support for strong protective measurements. With this initial finding, more research could be conducted to replicate this relationship.

The current study is not without limitations. First, the survey adopted a cross-sectional design in which all of the responses were collected at the same time. This might cause endogenous concern, prohibit any form of causal inference, and introduce cofounders as common method bias. Second, the current study was conducted already after the most severe period of the pandemic when some of the extremely strong measures have already been canceled. Therefore, it might be possible that the level of support to strong measures, as included in the current study, over-estimate the true level of support.

Finally, we propose some directions for future research. First, to make a stronger and more appropriate causal inference, future studies could utilize a longitudinal design and (or) an experimental design. Second, another important factor that might influence one's support to the strong measures in the subjective measurement of Social and economic status (SES) as it was as consistently found to be positively related to mental health (Quon \& McGrath, 2014) [12]. Future studies could further examine the role of SES on the level of support to strong preventive measures. Last, as the current study is restricted to the Chinese sample, the conclusion might not be directly generalizable to other countries. We expect future research could take up the 
challenges and replicate the current findings in the various sample.

\section{REFERENCES}

[1] Gruber, J., Prinstein, M. J., Clark, L. A., Rottenberg, J., Abramowitz, J. S., Albano, A. M., ... \& Forbes, E. E. (2020). Mental health and clinical psychological science in the time of COVID-19: Challenges, opportunities, and a call to action. American Psychologist.

[2] Haidt, J., McCauley, C., \& Rozin, P. (1994). Individual differences in sensitivity to disgust: A scale sampling seven domains of disgust elicitors. Personality and Individual differences, 16(5), 701-713.

[3] Inbar, Y., Pizarro, D., Iyer, R., \& Haidt, J. (2012). Disgust sensitivity, political conservatism, and voting. Social Psychological and Personality Science, 3(5), 537-544.

[4] Wheaton, M. G., Abramowitz, J. S., Berman, N. C., Fabricant, L. E., \& Olatunji, B. O. (2012). Psychological predictors of anxiety in response to the H1N1 (swine flu) pandemic. Cognitive Therapy and Research, 36(3), 210-218.

[5] Beall, A. T., Hofer, M. K., \& Schaller, M. (2016). Infections and elections: Did an Ebola outbreak influence the 2014 US federal elections (and if so, how)?. Psychological Science, 27(5), 595-605.

[6] Cox, R. C., Jessup, S. C., Luber, M. J., \& Olatunji, B. O. (2020). Pre-pandemic disgust proneness predicts increased coronavirus anxiety and safety behaviors: Evidence for a diathesis-stress model. Journal of anxiety disorders, 102315.

[7] Díaz, R., \& Cova, F. (2020). Moral values and trait pathogen disgust predict compliance with official recommendations regarding COVID-19 pandemic in US samples.

[8] Sahar, G. (2008). Patriotism, attributions for the 9/11 attacks, and support for war: Then and now. Basic and Applied Social Psychology, 30(3), 189-197.

[9] Barnes, C. D., Brown, R. P., Lenes, J., Bosson, J., \& Carvallo, M. (2014). My country, my self: Honor, identity, and defensive responses to national threats. Self and Identity, 13(6), 638-662.

[10] Buuren, S. V., \& Groothuis-Oudshoorn, K. (2010). mice: Multivariate imputation by chained equations in R. Journal of statistical software, 1-68.

[11] Schatz, R. T., Staub, E., \& Lavine, H. (1999). On the varieties of national attachment: Blind versus constructive patriotism. Political Psychology, 20(1), 151-174.

[12] Quon, E. C., \& McGrath, J. J. (2014). Subjective socioeconomic status and adolescent health: a metaanalysis. Health Psychology, 33(5), 433. 